\title{
Recent Developments in Graphene-Based Toxic Gas Sensors: A Theoretical Overview
}

\author{
Heriberto Cruz-Martínez ${ }^{1}$ (D) , Hugo Rojas-Chávez ${ }^{2}$ (D) Fernando Montejo-Alvaro ${ }^{1}$, Yesica A. Peña-Castañeda ${ }^{3}$, \\ Pastor T. Matadamas-Ortiz ${ }^{4, *}$ and Dora I. Medina ${ }^{5, *(D)}$
}

1 Tecnológico Nacional de México, Instituto Tecnológico del Valle de Etla, Abasolo S/N, Barrio del Agua Buena, Santiago Suchilquitongo, Oaxaca 68230, Mexico; heri1234@hotmail.com (H.C.-M.); moaf1217@gmail.com (F.M.-A.)

2 Tecnológico Nacional de México, Instituto Tecnológico de Tláhuac II, Camino Real 625, Tláhuac, Ciudad de México 13508, Mexico; rojas_hugo@ittlahuac2.edu.mx

3 Colegio de Ciencia y Tecnología, Universidad Autónoma de la Ciudad de México, Av. Fray Servando Teresa de Mier 92, Cuauhtémoc, Ciudad de México 06080, Mexico; yesica.pena@uacm.edu.mx

4 Instituto Politécnico Nacional, CIIDIR-OAXACA, Hornos No. 1003, Noche Buena, Santa Cruz Xoxocotlán 71230, Mexico

5 Tecnologico de Monterrey, School of Engineering and Sciences, Atizapan de Zaragoza, Estado de México 52926, Mexico

* Correspondence: pmatadamaso@ipn.mx (P.T.M.-O.); dora.medina@tec.mx (D.I.M.)

check for updates

Citation: Cruz-Martínez, H.; Rojas-Chávez, H.; Montejo-Alvaro, F.; Peña-Castañeda, Y.A.;

Matadamas-Ortiz, P.T.; Medina, D.I. Recent Developments in Graphene-Based Toxic Gas Sensors: A Theoretical Overview. Sensors 2021, 21, 1992. https://doi.org/10.3390/ s21061992

Academic Editor: Najla Fourati

Received: 31 January 2021

Accepted: 22 February 2021

Published: 11 March 2021

Publisher's Note: MDPI stays neutral with regard to jurisdictional claims in published maps and institutional affiliations.

Copyright: (c) 2021 by the authors. Licensee MDPI, Basel, Switzerland. This article is an open access article distributed under the terms and conditions of the Creative Commons Attribution (CC BY) license (https:// creativecommons.org/licenses/by/ $4.0 /)$.

\begin{abstract}
Detecting and monitoring air-polluting gases such as carbon monoxide (CO), nitrogen oxides $\left(\mathrm{NO}_{\mathrm{x}}\right)$, and sulfur oxides $\left(\mathrm{SO}_{\mathrm{x}}\right)$ are critical, as these gases are toxic and harm the ecosystem and the human health. Therefore, it is necessary to design high-performance gas sensors for toxic gas detection. In this sense, graphene-based materials are promising for use as toxic gas sensors. In addition to experimental investigations, first-principle methods have enabled graphene-based sensor design to progress by leaps and bounds. This review presents a detailed analysis of graphenebased toxic gas sensors by using first-principle methods. The modifications made to graphene, such as decorated, defective, and doped to improve the detection of $\mathrm{NO}_{\mathrm{x}}, \mathrm{SO}_{\mathrm{x}}$, and $\mathrm{CO}$ toxic gases are revised and analyzed. In general, graphene decorated with transition metals, defective graphene, and doped graphene have a higher sensibility toward the toxic gases than pristine graphene. This review shows the relevance of using first-principle studies for the design of novel and efficient toxic gas sensors. The theoretical results obtained to date can greatly help experimental groups to design novel and efficient graphene-based toxic gas sensors.
\end{abstract}

Keywords: pristine graphene; defective graphene; doped graphene; density functional theory; first principle studies; toxic gas sensors; adsorption energy

\section{Introduction}

The conversion of energy from one form to another many times affects the air composition in several ways. It is well-known that fossil fuels have been powering industrial development and the amenities of modern life that we enjoy. However, the combustion of fossil fuels contributes to a great extent to composition variations of the atmosphere, and this is mainly due to harmful gas emissions.

Harmful gases include, for instance, aliphatic hydrocarbons, carbon monoxide (CO), nitrogen oxides $\left(\mathrm{NO}_{\mathrm{x}}\right)$, and sulfur oxides $\left(\mathrm{SO}_{\mathrm{x}}\right)$, among others. In this context, health expenditures have increased due to air pollution, which is mainly associated with the rapid industrialization of many countries. Consequently, the disruption of ecological balance and serious public health issues caused by harmful gases are raising global concerns [1,2]. Table 1 illustrates some aspects about the harmful effects of toxic gases related to human health. 
Table 1. Main toxic inhalation hazards.

\begin{tabular}{ccclc}
\hline Gas or Vapor & Irritate & Odor & \multicolumn{1}{c}{ Signs and Symptoms } & Refs. \\
\hline $\begin{array}{c}\text { Carbon } \\
\text { monoxide }\end{array}$ & No & No & $\begin{array}{l}\text { Tissue hypoxia, hypoxic cardiac } \\
\text { dysfunction, subtle cardiovascular, } \\
\text { unconsciousness, and death after } \\
\text { prolonged exposures or after acute } \\
\text { exposures to high concentrations of CO. }\end{array}$ & {$[3-5]$} \\
Nitrogen oxides & Yes & No & $\begin{array}{l}\text { Nausea, headache, respiratory illness } \\
\text { (cough and irritation of the respiratory } \\
\text { tract), asthma, pneumonia, possibly } \\
\text { tuberculosis, and Parkinson's disease. }\end{array}$ & {$[6-9]$} \\
\hline Sulfur oxides & Yes & Yes & $\begin{array}{l}\text { Neurological damage, bronchitis, } \\
\text { bronchial asthma, emphysema, } \\
\text { bronchoconstriction and mucus. }\end{array}$ & {$[3,4,10,11]$} \\
\hline
\end{tabular}

On the other hand, until today, a sizable number of countries depend on oil for energy uses and development. Consequently, harmful effects on the environment such as global warming, ozone depletion, acid rain and climate change may result from the gases emanating from fossil fuel combustion. Therefore, harmful gases do not only affect human health, but they also have an undesirable impact on the environment.

According to Springer, the greenhouse effect of the troposphere is beneficial because it makes the earth habitable at an overall average temperature of about $15^{\circ} \mathrm{C}$ [12] (see Figure 1). However, higher concentrations of $\mathrm{CO}_{2}$, methane, water vapor, chlorofluorocarbons (CFCs), ozone, and nitrous oxide in the upper atmosphere could result in global warming, accompanied by economic and environmental implications [12-16].

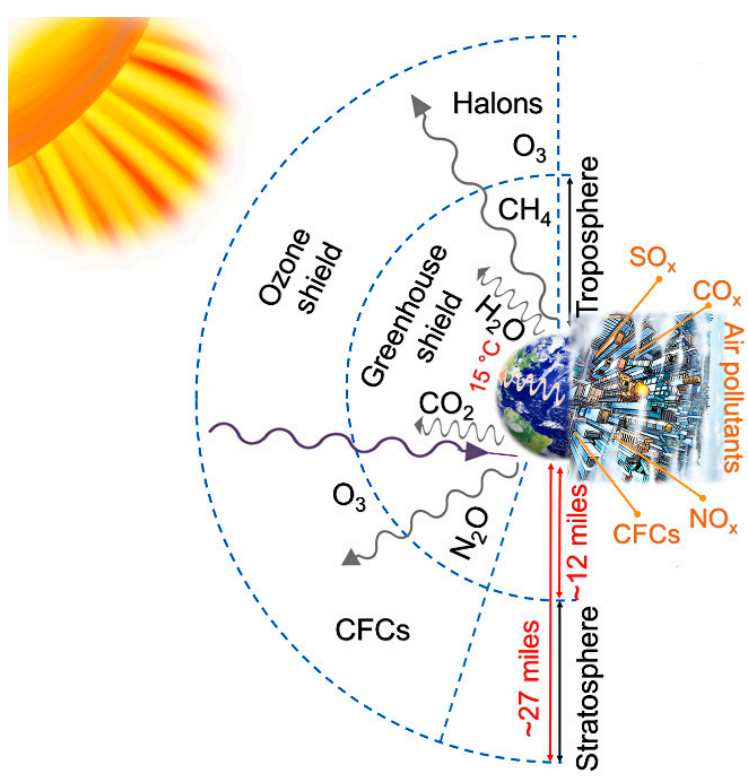

Figure 1. Model of the Earth's gaseous protective shield [12,16].

Against this backdrop, effectively sensing and capturing these harmful gases, such as $\mathrm{CO}, \mathrm{NO}_{\mathrm{x}}$, and $\mathrm{SO}_{\mathrm{x}}$, can greatly help protect the environment and human health $[9,17]$. Nowadays many materials, such as metal oxide semiconductors, conducting polymers, carbon-based materials, have been investigated and utilized as toxic gas sensors [18-20]. However, the challenges of these gas sensors can be one or more of the following: cost, sensitivity (e.g., ppb level is rare), and poor selectivity, among others [19]. Therefore, it is necessary to design high-performance gas sensors for detecting these toxic gases. As an alternative, among the carbon materials, graphene, a 2D monolayer form of $\mathrm{sp}^{2}$-hybridized 
carbon atoms, could prove a key material for sensing applications due to its exceptional thermal conductivity, high electron mobility, excellent mechanical properties, and high specific surface area [21-24]. Due to its remarkable properties, graphene opens up a wide range of promising applications in the sensors field, from fundamental science to industrial applications [25-29]. However, the main issue is that gas molecules are weakly adsorbed on graphene due to its low reactivity [30-32]. For this reason, both at the theoretical and experimental levels, several strategies have been developed to modify the electronic and structural properties of graphene and, consequently, improve its reactivity toward the toxic gases. Such strategies include doped, decorated, defective, and functionalized graphene [33-35].

Experimentally, the current conception of novel graphene sensor materials and the required performance improvements are largely limited by lack of rapid and economical synthesis routes and post-testing strategies to ensure their functionality. Currently, different synthesis techniques such as chemical vapor deposition, sputtering, drop casting, spin coating, and inkjet printing have been used to fabricate high quality graphene for the detection of toxic gases [36,37]. However, many of these methods are expensive and not easily scalable for mass production. In addition, it is difficult to control the doping concentration and the number of graphene layers. Undoubtedly, such limitations can be overcome if sensor materials are designed, modeled, and evaluated from a theoretical point of view (e.g., first-principle methods). The first-principle or ab initio methods are based on the quantum mechanics theory. Specifically, the density functional theory (DFT) is primarily a formalism of electronic ground state structure, couched in terms of the electronic density distribution [38]. The DFT-based simulations are essential for explaining and understanding the experimental results at the molecular level, or as a predictive tool for the rational design of novel gas sensors [39]. The DFT calculations provide important information, such as the adsorption mechanisms, the adsorption energy, charge transfer, electronic modification after gas adsorption, feasible approaches to enhance adsorption or desorption, that are critical for designing novel gas sensors [40]. Due to the critical role that theoretical calculations have in the design of toxic gas sensors, numerous DFT studies have been conducted to investigate novel graphene-based gas sensors. However, to date there are no detailed and critical reviews of the current progress in theoretical design of graphene-based toxic gas sensors; state-of-the-art reviews mainly focus on experimental evidence $[28,29,41,42]$. Therefore, this review presents a detailed and critical analysis of the progress of graphene-based toxic gas sensors by using first-principle methods. The modifications made to graphene, such as defective, doped, and decorated to improve the detection of $\mathrm{CO}$ and $\mathrm{NO}_{\mathrm{x}}$, and $\mathrm{SO}_{\mathrm{x}}$ toxic gases, are revised and analyzed in detail.

\section{Pristine Graphene}

Different approaches have been used for theoretical studies into pristine graphene, such as aromatic molecules (finite system) and periodic systems (supercell) (see Figure 2). There have been several theoretical studies conducted on the use of pristine graphene as a toxic gas sensor [43-46]. One of the first DFT-based studies on the use of pristine graphene as a toxic gas sensor was performed by Leenaerts et al. [43]. They investigated the adsorption of $\mathrm{CO}, \mathrm{NO}_{2}$, and $\mathrm{NO}$ on pristine graphene using a $4 \times 4$ graphene supercell with the generalized gradient approximation (GGA), specifically the Perdew-Burke-Ernzerhof (PBE) functional; the adsorption energies of $-14,-67$, and $-29 \mathrm{meV}$ were found for $\mathrm{CO}$, $\mathrm{NO}_{2}$, and $\mathrm{NO}$ molecules, respectively [43]. At the same time, Wehling et al. conducted the first joint experimental and theoretical investigation of the $\mathrm{NO}_{2}$ adsorption on graphene. To this end, they used the local density approximation (LDA) and the GGA for their calculations [44]. The computed $\mathrm{NO}_{2}$ adsorption energy with the GGA method was similar to that reported by Leenaerts et al. [43]. However, the $\mathrm{NO}_{2}$ adsorption energy calculated using the LDA method was higher that the computed energy that employed the GGA method [44]. In another investigation, Lin et al. studied the $\mathrm{CO}$, and $\mathrm{NO}_{2}$ adsorption on graphene using a $4 \times 4$ graphene supercell with the van der Waals density functional 
(vdW-DF2) and LDA methods [45]. The $\mathrm{CO}$ and $\mathrm{NO}_{2}$ adsorption energies calculated by vdW-DF2 were larger than those obtained by LDA [45]. For the adsorption mechanism of the toxic gases on the pristine graphene, for the $\mathrm{CO}$ and $\mathrm{NO}$ molecules, the most stable interaction occurs when the $\mathrm{CO}[43,45]$ and $\mathrm{NO}[43]$ molecules are parallel to the graphene surface, whereas for the $\mathrm{NO}_{2}$ molecule, the most stable interaction is with the $\mathrm{O}$ atoms of the $\mathrm{N}-\mathrm{O}$ bonds pointing toward the graphene surface [43-45]. Although the adsorption energies of the gases on graphene are notably affected by the methods employed [44-46], the interaction between gases and pristine graphene is weak [43]. This could limit the sensitivity of pristine graphene to detecting toxic gases.

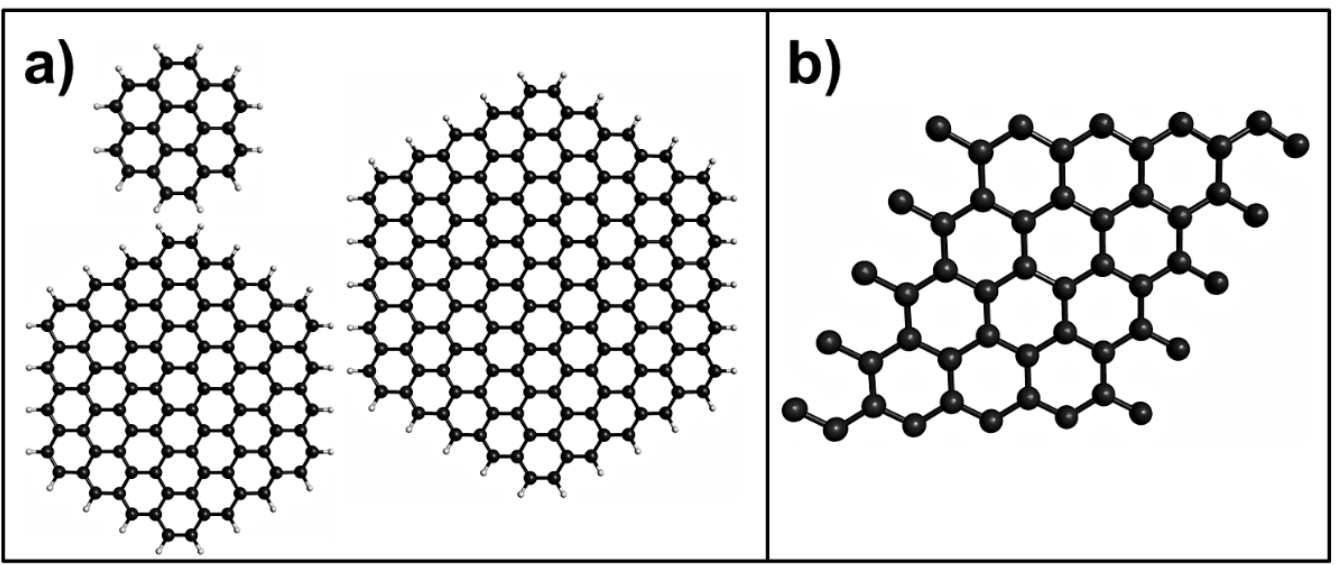

Figure 2. Models of graphene used for the density functional theory (DFT) calculations: (a) aromatic molecules, (b) graphene supercell. Black and gray spheres represent $\mathrm{C}$ and $\mathrm{H}$ atoms, respectively.

\section{Pristine Graphene Decorated with Transition Metals}

To date, researchers have employed different strategies for improving the reactivity of pristine graphene toward the detection of toxic gases. One of these strategies is the use of pristine graphene decorated with transition metals. This strategy involves the deposition of transition metal atoms onto the pristine graphene. To date, various DFT studies on toxic gas adsorption on pristine graphene decorated with transition metals are available in the literature [47-51]. In the first instance, the $\mathrm{CO}, \mathrm{NO}$, and $\mathrm{SO}_{2}$ adsorption on Co-decorated graphene was studied [47]. Lately, the $\mathrm{NO}$ [48] and $\mathrm{SO}_{2}$ [49] adsorption on Pt-decorated graphene was investigated. In another study, the $\mathrm{CO}$ and $\mathrm{NO}$ adsorption on Li-decorated graphene was calculated [50]. Finally, the $\mathrm{NO}_{2}$ adsorption on $\mathrm{Ni}-$, $\mathrm{Pd}-$, and Pt-decorated graphene was computed [51]. On the interaction mechanism between the toxic gases and graphene decorated with transition metals; for the $\mathrm{CO}$ and $\mathrm{NO}$ molecules, the most stable interaction occurs when the CO $[47,50]$ and $\mathrm{NO}[47,48,50]$ molecules are vertical to the graphene decorated with transition metals. Furthermore, it has been reported that the atom type used to decorate the graphene can influence on the adsorption mechanism between the toxic gas and the graphene [51]. For instance, the mode of $\mathrm{NO}_{2}$ adsorption on the graphene decorated with $\mathrm{Ni}$ is different with respect to the graphene decorated with $\mathrm{Pd}$ and $\mathrm{Pt}$ (see Figure 3).

The adsorption energies of toxic gases on graphene decorated with transition metals is much higher than those on pristine graphene (see Table 2). Such increments in the adsorption energy can be attributed to the modification of the electronic properties of transition metals-decorated graphene compared to undecorated pristine graphene. For example, a high charge transfer from metallic atoms to the graphene has been observed, which improves the reactivity of pristine graphene [48,49]. All previous results demonstrated that the toxic gases adsorption energies were enhanced on graphene decorated with transition metals compared to the adsorption energies on pristine graphene. This shows that pristine graphene decorated with transition metals is a promising material for use in toxic gas sensors. However, to date, DFT studies on the selectivity of graphene decorated with 
transition metals toward toxic gases have scarcely been reported in literature. Therefore, more theoretical studies on the selectivity of pristine graphene decorated with transition metals should be carried out.

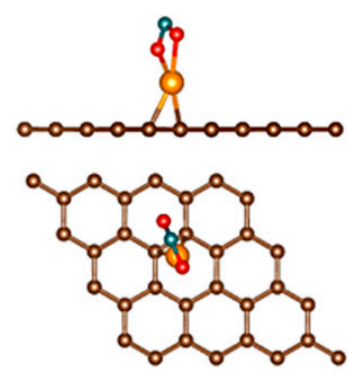

(a)

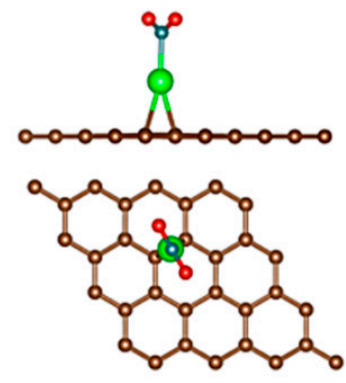

(b)

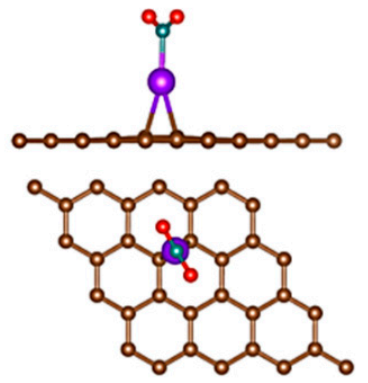

(c)

Figure 3. Top view (top) and side view (bottom) of optimized geometry for $\mathrm{NO}_{2}$ adsorbed on (a) $\mathrm{Ni}$ /graphene decorated with Ni, (b) graphene decorated with Pd, and (c) graphene with Pt. Figure obtained from [51].

Table 2. Adsorption energies of toxic gases on transition metals decorated graphene.

\begin{tabular}{cccccc}
\hline Material & Gas & E $_{\text {ads }}(\mathbf{i n ~} \mathbf{~ V V})$ & Functional & Approach & Refs. \\
\hline Co-decorated graphene & $\mathrm{CO}$ & -2.19 & $\mathrm{PBE}$ & Supercell & {$[47]$} \\
Co-decorated graphene & $\mathrm{NO}$ & -4.04 & $\mathrm{PBE}$ & Supercell & {$[47]$} \\
Co-decorated graphene & $\mathrm{SO}_{2}$ & -2.35 & $\mathrm{PBE}$ & Supercell & {$[47]$} \\
Pt-decorated graphene & $\mathrm{NO}$ & -2.06 & $\mathrm{~B} 3 \mathrm{LYP}$ & Supercell & {$[48]$} \\
Pt-decorated graphene & $\mathrm{NO}_{2}$ & -2.00 & PBE & Supercell & {$[51]$} \\
Pt-decorated graphene & $\mathrm{SO}_{2}$ & -1.58 & B3LYP & Supercell & {$[49]$} \\
Li-decorated graphene & $\mathrm{CO}$ & -0.55 & B3LYP & Finite system & {$[50]$} \\
Li-decorated graphene & $\mathrm{NO}$ & -0.14 & B3LYP & Finite system & {$[50]$} \\
Ni-decorated graphene & $\mathrm{NO}_{2}$ & -2.63 & PBE & Supercell & {$[51]$} \\
Pd-decorated graphene & $\mathrm{NO}_{2}$ & -1.59 & PBE & Supercell & {$[51]$} \\
\hline
\end{tabular}

\section{Defective Graphene}

Another strategy employed to modify the reactivity of pristine graphene is through defects. As has been reported in literature, nanoscale defects bring new functionalities that could be useful for different applications. For instance, structural defects notably modify the mechanical, chemical, and electronic properties of graphene [52]. At the theoretical level, structural defects have become very important to modify the graphene reactivity because these can be introduced into graphene during synthesis by chemical treatment or irradiation $[52,53]$. To date, there have been various theoretical studies conducted on the use of defective graphene as toxic gas sensor [54-65]. For instance, Huang et al. investigated the $\mathrm{CO}, \mathrm{NO}, \mathrm{NO}_{2}$ on armchair graphene nanoribbons (AGNRs) with edge dangling bond defects using PW91 functional (see Figure 4). The $\mathrm{CO}, \mathrm{NO}$, and $\mathrm{NO}_{2}$ adsorption energies were $-1.34,-2.29$, and $-2.70 \mathrm{eV}$, respectively. These results indicate that the toxic gas adsorption at AGNR edges is stronger than on graphene surface [56]. To date, different defects have been introduced in the graphene surface to improve its reactivity toward the toxic gases, see Table 3. The single-vacancy and Stone-Wales defects have been used to modify the graphene surface. The single-vacancy has been the defect mostly studied. The single-vacancy defects in graphene have been found to have stronger interactions with toxic gases compared to pristine graphene. This shows that graphene with single-vacancy defects is a promising material for use in toxic gases sensors. The good sensitivity of graphene with single-vacancy defects is attributed to the modified electronic properties compared to those of pristine graphene. The removed $\mathrm{C}$ atom produces the three neighboring $\mathrm{C}$ atoms having three dangling bonds, which produce localized states at the Fermi level $[59,63]$. For the adsorption mechanism of the toxic gases on the graphene 
with a single-vacancy; in the case of $\mathrm{CO}$ and $\mathrm{NO}$ molecules, the most stable adsorption occurs when the $\mathrm{C}$ and $\mathrm{N}$ atoms of the $\mathrm{CO}[57-61]$ and $\mathrm{NO}[57,58,60,63]$ molecules are in the vacancy of graphene, respectively, whereas for the $\mathrm{NO}_{2}$ and $\mathrm{SO}_{2}$ molecules, the most stable interaction occurs when the $\mathrm{NO}_{2}\left[58\right.$ ] and $\mathrm{SO}_{2}$ [64] molecules are vertical to the defective graphene with the $\mathrm{N}$ and $\mathrm{S}$ atoms toward the vacancy of graphene, respectively.

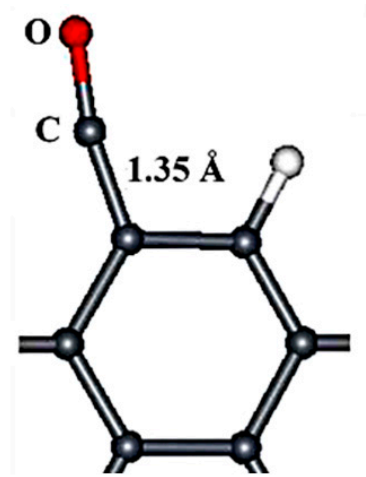

(a)

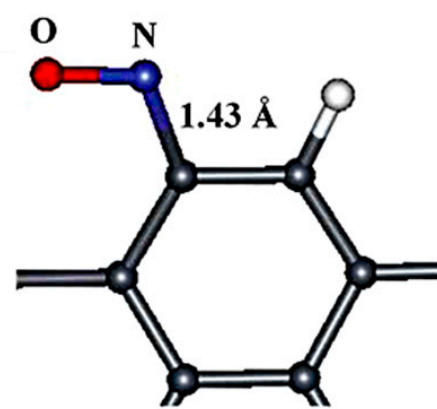

(b)

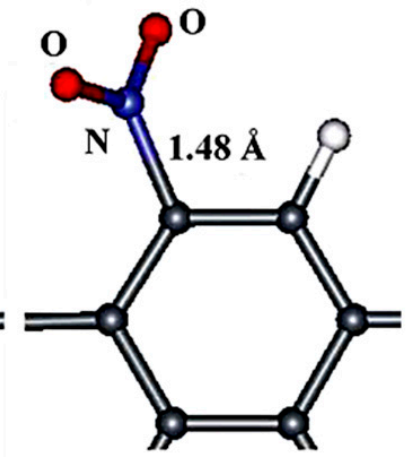

(c)

Figure 4. Optimized structures of armchair graphene nanoribbons (AGNRs) with gas molecules: (a) $\mathrm{CO},(\mathbf{b}) \mathrm{NO}$, and (c) $\mathrm{NO}_{2}$. It only shows the structure around the adsorbed molecule. Gray, white, red, and blue spheres represent $\mathrm{C}, \mathrm{H}, \mathrm{O}$, and $\mathrm{N}$ atoms, respectively. Figure modified from [56].

Table 3. Adsorption energies of toxic gases on defective graphene.

\begin{tabular}{|c|c|c|c|c|c|}
\hline Material & Gas & $\mathrm{E}_{\text {ads }}($ in eV) & Functional & Approach & Refs. \\
\hline Single vacancy & $\mathrm{CO}$ & -6.05 & GGA & Supercell & [57] \\
\hline Single vacancy & $\mathrm{CO}$ & -2.33 & CA-PZ & Supercell & [58] \\
\hline Single vacancy & $\mathrm{CO}$ & $\begin{array}{c}-5.06^{\mathrm{a}} \\
-5.15\end{array}$ & PBE & Supercell & [59] \\
\hline Single vacancy & $\mathrm{CO}$ & -0.07 & PBE & Supercell & {$[60]$} \\
\hline Single vacancy & $\mathrm{CO}$ & -1.86 & PBE & Supercell & [61] \\
\hline Single vacancy & $\mathrm{CO}$ & -0.18 & PBE & Supercell & [62] \\
\hline Single vacancy & $\mathrm{NO}$ & -6.64 & GGA & Supercell & [57] \\
\hline Single vacancy & NO & -3.04 & CA-PZ & Supercell & [58] \\
\hline Single vacancy & NO & -1.20 & PBE & Supercell & [60] \\
\hline Single vacancy & NO & -8.25 & PBE & Supercell & [63] \\
\hline Single vacancy & $\mathrm{NO}_{2}$ & -3.04 & CA-PZ & Supercell & [58] \\
\hline Single vacancy & $\mathrm{NO}_{2}$ & $-6.41^{b}$ & PBE & Supercell & [63] \\
\hline Single vacancy & $\mathrm{SO}_{2}$ & -2.38 & PBE & Supercell & [64] \\
\hline Stone-Wales & $\mathrm{CO}$ & $-1.30^{\mathrm{a}}$ & & Supercell & [59] \\
\hline Stone-Wales & $\mathrm{SO}_{2}$ & -0.19 & PBE & Supercell & [65] \\
\hline
\end{tabular}

a Results obtained using self-consistent-charge density-functional tight-binding method. ${ }^{\mathrm{b}} \mathrm{The}^{\mathrm{NO}} \mathrm{N}_{2}$ dissociation into $\mathrm{O}$ and $\mathrm{NO}$ was observed.

It has also been shown that an extra electric field serves as a good strategy to enhance the reactivity of defective graphene toward the toxic gases, as it positively affects the material's electronic properties [61]. Recently, the $\mathrm{CO}$ adsorption on a graphene sheet with single-vacancy defects under different electric fields was investigated [61]. The calculated adsorption energies of $\mathrm{CO}$ on the single-vacancy defective graphene under an applied electric field of -0.016 a.u. was $62.6 \%$ higher than without the electric field [61], which shows that an external electric field offers a good way to enhance the reactivity of defective graphene toward the toxic gases.

When toxic gas sensors are exposed to aerobic environments, interference from other gases will cause false alarms [57]. Therefore, it is essential to explore the selectivity of the graphene-based sensors toward the toxic gases. In this direction, Ma et al. demonstrated that $\mathrm{CO}$ and $\mathrm{O}_{2}$ molecules are chemisorbed on graphene with single-vacancy 
defects. This limits selectively toward the $\mathrm{CO}$ since $\mathrm{O}_{2}$ chemisorption would lead to a false alarm [57]. In another study, the selectivity of graphene with a single-vacancy defect toward the various gases was investigated (e.g., $\mathrm{H}_{2}, \mathrm{~N}_{2}, \mathrm{O}_{2}, \mathrm{CO}, \mathrm{CO}_{2}, \mathrm{H}_{2} \mathrm{O}, \mathrm{H}_{2} \mathrm{~S}$, and $\mathrm{NH}_{3}$ ). Five gases $\left(\mathrm{H}_{2}, \mathrm{O}_{2}, \mathrm{CO}, \mathrm{CO}_{2}\right.$, and $\left.\mathrm{NH}_{3}\right)$ exhibited chemisorption, whereas the remaining gases showed physisorption $\left(\mathrm{N}_{2}, \mathrm{H}_{2} \mathrm{O}\right.$, and $\left.\mathrm{H}_{2} \mathrm{~S}\right)$. For the $\mathrm{H}_{2}, \mathrm{O}_{2}, \mathrm{CO}_{2}$, and $\mathrm{NH}_{3}$ chemisorption involves the dissociation of the molecules; namely, $\mathrm{O}_{2} \rightarrow \mathrm{O}+\mathrm{O}$. It is remarkable that only the $\mathrm{CO}$ molecule remains without dissociation. Therefore, the graphene with a single-vacancy would be more selective toward the $\mathrm{CO}$ detection. For instance, it is observed that the $\mathrm{O}_{2}$ molecule requires about $5.11 \mathrm{eV}$ to get dissociated and then bind to the vacancy. Whereas the $\mathrm{CO}$ molecule avoids paying that huge dissociation energy. This fact shows that graphene with a single-vacancy defect has a higher selectivity toward the CO detection [59].

\section{Doped Graphene}

Another approach widely used to modify the reactivity of pristine graphene is through doping. Doping atoms proved to substantially modify the electronic, chemical, and structural properties of pristine graphene $[66,67]$. At the theoretical level, there are various routes to dope the graphene sheet. A widely used method is to replace a carbon atom with the doping atom in the graphene sheet. Currently, different doped-graphene sheets have been explored as toxic gas sensors, replacing a carbon atom by a dopant atom [55,68-100]. Around 30 elements of the periodic table have been explored for use as doping materials, with $\mathrm{N}$ being the most studied element dopant due to its similar atomic radii with $\mathrm{C}$ (see Table 4). Among the toxic gases reviewed, $\mathrm{CO}$ gas is the most investigated due its high toxicity in humans [101]. It is also observed that the GGA (specifically PBE) method and supercell approach are the most widely approaches used for studying doped graphene for use in toxic gas sensors. Interestingly, several studies consider dispersion corrections in the calculations to better describe the interaction between the toxic gases and doped graphene. According to adsorption energies of the toxic gases, in most cases, it is observed that the toxic gases were adsorbed stronger on doped graphene than on pristine graphene. This shows that the doped-graphene sheets are good candidates as toxic gas sensors. The increase in the adsorption energy can be attributed to the modification of the structural and electronic properties of doped graphene compared to pristine graphene. For instance, a high charge transfer from metallic atoms to the graphene has been observed, which improves the reactivity of doped graphene toward the toxic gases [71,85,99]. However, in some cases, the interaction between the toxic gases and the doped-graphene sheet has been reported to be low, as in the case of the interaction of CO on the N-doped graphene. For the adsorption mechanism of the toxic gases on the doped graphene, it has been reported that the atom type used to dope the graphene can influence on the adsorption mechanism between the toxic gas and the graphene $[69,71]$. Finally, although all calculations are conducted at the DFT level, there are discrepancies between the results reported (e.g., $\mathrm{NO}_{2}$ adsorption energies on the $\mathrm{N}$-doped graphene) in Table 4 . These can be attributed to various factors, such as the functional and dispersion corrections employed in the calculations, the type and site of gas adsorption on which the adsorption energy was calculated, among others.

An extra electric field could be a good strategy to enhance the reactivity of graphenebased gas sensors [61]. In this sense, the $\mathrm{CO}$ adsorption on Al-doped graphene under different electric fields was investigated [83]. The calculated adsorption energies of $\mathrm{CO}$ on the Al-doped graphene under an applied electric field of -0.03 a.u. were higher than those without the electric field [83]. This indicates that an external electric field is a good way to enhance the reactivity of doped graphene toward the toxic gases $[83,95]$. It can also be used for the desorption of toxic gases on the sensor surface, only modifying the direction of the electric field. In this context, the $\mathrm{NO}$ and $\mathrm{NO}_{2}$ adsorption on Fe-doped graphene under different electric fields (0.01-0.05 a.u.) was investigated [79]. Electric fields above 0.03 a.u. have been found to cause $\mathrm{NO}$ and $\mathrm{NO}_{2}$ desorption from the surface of 
Fe-doped graphene [79]. CO desorption from the Al-doped-graphene surface has also been demonstrated under the application of an electric field $\geq 0.03$ a.u. [83]. Therefore, an electric field can be employed to reactivate the doped-graphene toxic gas sensors for repetitious applications.

Table 4. Adsorption energies of toxic gases on doped graphene.

\begin{tabular}{|c|c|c|c|c|c|}
\hline Material & Gas & $E_{\text {ads }}($ in eV) & Functional & Approach & Refs. \\
\hline N-doped & $\mathrm{CO}$ & -0.14 & CA-PZ & Supercell & [58] \\
\hline N-doped & $\mathrm{CO}$ & -0.03 & PBE & Supercell & [68] \\
\hline N-doped & $\mathrm{CO}$ & -0.13 & PBE & Finite system & [69] \\
\hline N-doped & $\mathrm{CO}$ & -0.01 & PBE & Supercell & [70] \\
\hline N-doped & $\mathrm{NO}$ & -0.40 & CA-PZ & Supercell & [58] \\
\hline N-doped & $\mathrm{NO}$ & -0.08 & PBE & Supercell & [68] \\
\hline N-doped & $\mathrm{NO}$ & -0.09 & PBE & Supercell & [70] \\
\hline N-doped & NO & 0.16 & PBE & Supercell & [71] \\
\hline N-doped & $\mathrm{NO}_{2}$ & -0.98 & CA-PZ & Supercell & [58] \\
\hline N-doped & $\mathrm{NO}_{2}$ & -0.26 & PBE & Supercell & [70] \\
\hline N-doped & $\mathrm{NO}_{2}$ & -0.44 & PBE & Supercell & [71] \\
\hline N-doped & $\mathrm{SO}_{2}$ & -0.29 & PBE & Supercell & [68] \\
\hline N-doped & $\mathrm{SO}_{2}$ & -0.19 & PBE & Supercell & [70] \\
\hline N-doped & $\mathrm{SO}_{2}$ & -0.17 & PW91 & Supercell & {$[72]$} \\
\hline N-doped & $\mathrm{SO}_{2}$ & -0.29 & B3LYP & Finite system & [73] \\
\hline N-doped & $\mathrm{SO}_{3}$ & -0.68 & B3LYP & Finite system & [73] \\
\hline Fe-doped & $\mathrm{CO}$ & -1.71 & PBE & Supercell & [74] \\
\hline Fe-doped & $\mathrm{CO}$ & -1.45 & PBE & Supercell & [75] \\
\hline Fe-doped & $\mathrm{CO}$ & -1.46 & B3LYP & Finite system & [76] \\
\hline Fe-doped & $\mathrm{CO}$ & -1.60 & PBE & Finite system & [77] \\
\hline Fe-doped & $\mathrm{CO}$ & -1.50 & B3LYP & Finite system & [78] \\
\hline Fe-doped & $\mathrm{NO}$ & -2.40 & PBE & Supercell & [74] \\
\hline Fe-doped & NO & -2.24 & PBE & Supercell & [75] \\
\hline Fe-doped & NO & -2.23 & PBE & Finite system & [79] \\
\hline Fe-doped & $\mathrm{NO}_{2}$ & -2.19 & PBE & Finite system & [79] \\
\hline Fe-doped & $\mathrm{NO}_{2}$ & -2.20 & PBE & Supercell & [80] \\
\hline Fe-doped & $\mathrm{SO}_{2}$ & -1.68 & PBE & Supercell & [74] \\
\hline Fe-doped & $\mathrm{SO}_{2}$ & -1.80 & PBE & Finite system & [77] \\
\hline Fe-doped & $\mathrm{SO}_{3}$ & -1.81 & PBE & Supercell & [80] \\
\hline B-doped & $\mathrm{CO}$ & -0.14 & CA-PZ & Supercell & [58] \\
\hline B-doped & $\mathrm{CO}$ & -0.13 & PBE & Finite system & [69] \\
\hline B-doped & $\mathrm{CO}$ & -0.02 & PBE & Supercell & [70] \\
\hline B-doped & NO & -1.07 & CA-PZ & Supercell & [58] \\
\hline B-doped & $\mathrm{NO}$ & -0.34 & PBE & Supercell & [70] \\
\hline B-doped & $\mathrm{NO}_{2}$ & -1.37 & CA-PZ & Supercell & [58] \\
\hline B-doped & $\mathrm{NO}_{2}$ & -0.33 & PBE & Supercell & [70] \\
\hline B-doped & $\mathrm{SO}_{2}$ & -0.03 & PBE & Supercell & [70] \\
\hline B-doped & $\mathrm{SO}_{2}$ & -0.21 & PW91 & Supercell & [72] \\
\hline B-doped & $\mathrm{SO}_{2}$ & -0.12 & B3LYP & Finite system & [81] \\
\hline B-doped & $\mathrm{SO}_{3}$ & -0.18 & B3LYP & Finite system & [81] \\
\hline Al-doped & $\mathrm{CO}$ & -0.77 & PBE & Finite system & [69] \\
\hline Al-doped & $\mathrm{CO}$ & -0.66 & PBE & Supercell & [70] \\
\hline Al-doped & $\mathrm{CO}$ & -4.98 & PBE & Supercell & [82] \\
\hline Al-doped & $\mathrm{CO}$ & $-0.57^{\mathrm{a}}$ & PBE & Supercell & [83] \\
\hline Al-doped & $\mathrm{CO}$ & -0.56 & B3LYP & Supercell & [84] \\
\hline Al-doped & NO & -1.35 & PBE & Supercell & {$[70]$} \\
\hline Al-doped & $\mathrm{NO}_{2}$ & -2.48 & PBE & Supercell & [70] \\
\hline Al-doped & $\mathrm{NO}_{2}$ & -0.65 & B3LYP & Supercell & [85] \\
\hline Al-doped & $\mathrm{SO}_{2}$ & -1.65 & PBE & Supercell & [65] \\
\hline Al-doped & $\mathrm{SO}_{2}$ & -1.54 & PBE & Supercell & [70] \\
\hline Al-doped & $\mathrm{SO}_{2}$ & -1.26 & PW91 & Supercell & [72] \\
\hline Pd-doped & $\mathrm{CO}$ & -0.91 & PBE & Supercell & [60] \\
\hline
\end{tabular}


Table 4. Cont.

\begin{tabular}{|c|c|c|c|c|c|}
\hline Material & Gas & $\mathrm{E}_{\text {ads }}($ in $\mathrm{eV})$ & Functional & Approach & Refs. \\
\hline Pd-doped & $\mathrm{CO}$ & -0.92 & B3LYP & Finite system & [76] \\
\hline Pd-doped & $\mathrm{CO}$ & -1.05 & PBE & Supercell & [86] \\
\hline Pd-doped & $\mathrm{CO}$ & -1.07 & PBE & Supercell & [87] \\
\hline Pd-doped & NO & -3.92 & PBE & Supercell & {$[60]$} \\
\hline Pd-doped & $\mathrm{NO}$ & -1.33 & PBE & Supercell & [82] \\
\hline Pd-doped & $\mathrm{NO}_{2}$ & -2.17 & PBE & Supercell & {$[87]$} \\
\hline Pd-doped & $\mathrm{NO}_{2}$ & -2.19 & PBE & Supercell & {$[87]$} \\
\hline Pd-doped & $\mathrm{SO}_{2}$ & -1.12 & PBE & Supercell & [87] \\
\hline Pd-doped & $\mathrm{SO}_{2}$ & -5.78 & PBE & Supercell & [88] \\
\hline Ni-doped & $\mathrm{CO}$ & -1.02 & B3LYP & Finite system & [76] \\
\hline Ni-doped & $\mathrm{CO}$ & -0.96 & B3LYP & Finite system & [78] \\
\hline Ni-doped & NO & -1.64 & PBE & Supercell & [89] \\
\hline Ni-doped & $\mathrm{NO}_{2}$ & -1.83 & PBE & Supercell & [89] \\
\hline Ni-doped & $\mathrm{SO}_{2}$ & -4.21 & PBE & Supercell & {$[88]$} \\
\hline Ni-doped & $\mathrm{SO}_{2}$ & -0.92 & PBE & Supercell & [89] \\
\hline Ni-doped & $\mathrm{SO}_{3}$ & -1.59 & PBE & Supercell & [89] \\
\hline Ti-doped & $\mathrm{CO}$ & -0.45 & PBE & Supercell & [68] \\
\hline Ti-doped & $\mathrm{CO}$ & -1.00 & B3LYP & Finite system & [78] \\
\hline Ti-doped & NO & -1.72 & PBE & Supercell & [68] \\
\hline Ti-doped & NO & -1.44 & PBE & Supercell & [71] \\
\hline Ti-doped & $\mathrm{NO}_{2}$ & -2.98 & PBE & Supercell & [71] \\
\hline Ti-doped & $\mathrm{SO}_{2}$ & -3.20 & PBE & Supercell & [68] \\
\hline Mn-doped & $\mathrm{CO}$ & -1.50 & PBE & Supercell & [62] \\
\hline Mn-doped & $\mathrm{CO}$ & -1.42 & B3LYP & Finite system & [78] \\
\hline Mn-doped & $\mathrm{NO}$ & -2.14 & PBE & Supercell & [90] \\
\hline Mn-doped & $\mathrm{NO}_{2}$ & -2.76 & PBE & Supercell & [90] \\
\hline Mn-doped & $\mathrm{SO}_{2}$ & -1.73 & PW91 & Supercell & [72] \\
\hline Mn-doped & $\mathrm{SO}_{2}$ & -1.83 & PBE & Supercell & {$[90]$} \\
\hline Co-doped & $\mathrm{CO}$ & -0.94 & B3LYP & Finite system & [76] \\
\hline Co-doped & $\mathrm{CO}$ & -0.94 & B3LYP & Finite system & [78] \\
\hline Co-doped & $\mathrm{CO}$ & -0.62 & PBE & Supercell & [47] \\
\hline Co-doped & NO & -1.51 & PBE & Supercell & [47] \\
\hline Co-doped & $\mathrm{SO}_{2}$ & -1.07 & PBE & Supercell & [47] \\
\hline Pt-doped & $\mathrm{CO}$ & -1.30 & B3LYP & Finite system & [76] \\
\hline Pt-doped & $\mathrm{NO}$ & -6.22 & PBE & Supercell & [91] \\
\hline Pt-doped & $\mathrm{NO}_{2}$ & -7.37 & PBE & Supercell & [91] \\
\hline Pt-doped & $\mathrm{NO}_{2}$ & -2.21 & PBE & Supercell & [92] \\
\hline Pt-doped & $\mathrm{SO}_{2}$ & -1.02 & PW91 & Supercell & [72] \\
\hline Pt-doped & $\mathrm{SO}_{2}$ & -1.06 & PBE & Supercell & [92] \\
\hline Si-doped & $\mathrm{CO}$ & -0.25 & PBE & Finite system & [69] \\
\hline Si-doped & NO & -0.82 & PBE & Supercell & [93] \\
\hline Si-doped & $\mathrm{NO}_{2}$ & -2.17 & PBE & Supercell & [93] \\
\hline Si-doped & $\mathrm{SO}_{2}$ & -0.90 & PW91 & Supercell & [72] \\
\hline P-doped & $\mathrm{CO}$ & -0.07 & PBE & Supercell & [94] \\
\hline P-doped & NO & -0.51 & PBE & Supercell & [94] \\
\hline P-doped & $\mathrm{NO}_{2}$ & -1.89 & PBE & Supercell & [94] \\
\hline P-doped & $\mathrm{SO}_{2}$ & -0.32 & PBE & Supercell & [94] \\
\hline S-doped & $\mathrm{CO}$ & -0.01 & PBE & Supercell & [70] \\
\hline S-doped & NO & -0.12 & PBE & Supercell & [70] \\
\hline S-doped & $\mathrm{NO}_{2}$ & -0.83 & PBE & Supercell & [70] \\
\hline S-doped & $\mathrm{SO}_{2}$ & -0.09 & PBE & Supercell & [70] \\
\hline Ga-doped & $\mathrm{CO}$ & -0.67 & PBE & Supercell & [95] \\
\hline Ga-doped & NO & -0.78 & PBE & Supercell & [95] \\
\hline Ga-doped & NO & -0.81 & PBE & Supercell & [96] \\
\hline Ga-doped & $\mathrm{NO}_{2}$ & -1.93 & PBE & Supercell & [95] \\
\hline Ag-doped & $\mathrm{NO}$ & -6.93 & PBE & Supercell & [91] \\
\hline Ag-doped & $\mathrm{NO}_{2}$ & -7.83 & PBE & Supercell & [91] \\
\hline Ag-doped & $\mathrm{SO}_{2}$ & -0.97 & PW91 & Supercell & [72] \\
\hline
\end{tabular}


Table 4. Cont.

\begin{tabular}{cccccc}
\hline Material & Gas & E $_{\text {ads }}(\mathbf{i n ~ e V})$ & Functional & Approach & Refs. \\
\hline Au-doped & $\mathrm{NO}$ & -8.47 & PBE & Supercell & {$[91]$} \\
Au-doped & $\mathrm{NO}_{2}$ & -9.34 & PBE & Supercell & {$[91]$} \\
Au-doped & $\mathrm{SO}_{2}$ & -1.28 & PW91 & Supercell & {$[72]$} \\
Cr-doped & $\mathrm{CO}$ & -1.63 & B3LYP & Finite system & {$[78]$} \\
Cr-doped & $\mathrm{SO}_{2}$ & -1.68 & PW91 & Supercell & {$[72]$} \\
Cr-doped & $\mathrm{SO}_{2}$ & $-1.59 \mathrm{~b}$ & PW91 & Supercell & {$[97]$} \\
Nb-doped & $\mathrm{CO}$ & -0.53 & PBE & Supercell & {$[98]$} \\
Nb-doped & $\mathrm{SO}_{2}$ & -0.32 & PBE & Supercell & {$[98]$} \\
Ta-doped & $\mathrm{NO}_{2}$ & -2.31 & PBE & Supercell & {$[99]$} \\
Ta-doped & $\mathrm{SO} 2$ & -1.68 & PBE & Supercell & {$[99]$} \\
Li-doped & $\mathrm{CO}$ & -3.51 & PBE & Supercell & {$[100]$} \\
Sc-doped & $\mathrm{CO}$ & -0.35 & B3LYP & Finite system & {$[78]$} \\
V-doped & $\mathrm{CO}$ & -0.55 & B3LYP & Finite system & {$[78]$} \\
Cu-doped & $\mathrm{CO}$ & -1.20 & B3LYP & Finite system & {$[78]$} \\
Zn-doped & $\mathrm{CO}$ & -0.67 & B3LYP & Finite system & {$[78]$} \\
Ru-doped & $\mathrm{CO}$ & -1.22 & B3LYP & Finite system & {$[76]$} \\
Rh-doped & $\mathrm{CO}$ & -1.01 & B3LYP & Finite system & {$[76]$} \\
In-doped & $\mathrm{CO}$ & -0.02 & PBE & Supercell & {$[61]$} \\
Sb-doped & $\mathrm{CO}$ & -0.01 & PBE & Supercell & {$[61]$} \\
Os-doped & $\mathrm{CO}$ & -1.80 & B3LYP & Finite system & {$[76]$} \\
Ir-doped & $\mathrm{CO}$ & -1.57 & B3LYP & Finite system & {$[76]$} \\
\hline
\end{tabular}

$\overline{{ }^{a}}$ Results obtained under electric field $=0.0$ a.u. ${ }^{\mathrm{b}}$ Adsorption energy calculated using zigzag graphene nanoribbons.

On the other hand, the selectivity of doped graphene toward the toxic gases has been investigated [77,79]. In this sense, Cortés-Arriagada et al. investigated the selectivity of Fe-doped graphene toward the $\mathrm{CO}$ and $\mathrm{SO}_{2}$ molecules in $\mathrm{O}_{2}$ environments [77]. They computed an $\mathrm{O}_{2}$ adsorption energy of $-1.68 \mathrm{eV}$, which is similar or higher than the energy absorption of $\mathrm{CO}$ and $\mathrm{SO}_{2}$ molecules. This limits selectively toward the $\mathrm{CO}$ and $\mathrm{SO}_{2}$ molecules in aerobic environments [77]. Another study examined the selectivity of Fe-doped graphene toward the $\mathrm{NO}$ and $\mathrm{NO}_{2}$ gases in $\mathrm{O}_{2}$ environments [79]. Results showed that Fe-doped graphene is selective toward the $\mathrm{NO}$ and $\mathrm{NO}_{2}$ molecules in $\mathrm{O}_{2}$ environments [79].

Another strategy for doping graphene has been to substitute various carbon atoms with the doping atoms. Figure 5a shows a graphene sheet with three atoms of $\mathrm{N}$ and a vacancy. This type of doping is known as pyridinic-type doping. Currently, there are some detailed studies on the use of pyridinic-type $\mathrm{N}$-doped graphene (PNG) as toxic gas sensors $[57,102]$. Ma et al. investigated toxic gas adsorption on PNG sheet using the GGA method [57]. They demonstrated that the PNG is a good candidate for selectively sensing $\mathrm{CO}$ from air [57]. Recently, the NO, and SO2 adsorption on PNG was investigated using the B3LYP approximation [102]. It was shown that the NO molecule is weakly adsorbed on PNG sheet $[57,102]$, which shows that PNG may not be a good candidate as a NO sensor. However, the $\mathrm{SO}_{2}$ gas is strongly adsorbed $(-2.58 \mathrm{eV})$, thus, PNG may be a good candidate as a $\mathrm{SO}_{2}$ sensor.

Another strategy employed to dope the graphene sheets is inserting the doping atom in a double vacancy (divacancy), see Figure 5b. These structures are interesting because they show better reactivity toward the toxic gases than defective graphene [60]. Consequently, there have been various studies on the use of doped vacancy-defected graphene as toxic gases sensors $[60,62,75,80,89]$. Jia et al. investigated the CO adsorption on Mn-doped vacancy-defected graphene using the PBE functional [62]. The CO adsorption energy on Mn-doped vacancy-defected graphene was higher than on defective or pristine graphene [62]. In another study, the $\mathrm{CO}$ and $\mathrm{NO}$ adsorption on Fe-doped vacancy-defected graphene was investigated using the PBE approximation [75]. Adsorption energies of -1.10 and $-2.41 \mathrm{eV}$ were computed for $\mathrm{CO}$ and $\mathrm{NO}$ on Fe-doped vacancy-defected graphene, respectively [75]. At the same time, Gao et al. computed the 
$\mathrm{NO}_{2}$ and $\mathrm{SO}_{3}$ interaction on Fe-doped vacancy-defected graphene employing the PBE functional (see Figure 6) [80]. Adsorption energies of $\mathrm{NO}_{2}(-1.59 \mathrm{eV})$ and $\mathrm{SO}_{3}(-1.39 \mathrm{eV})$ were investigated on Fe-doped vacancy-defected graphene [80]. Recently, Ni-doped vacancydefected graphene sheets were studied as toxic gases sensors considering the PBE functional [89]. The computed results indicate that $\mathrm{NO}(-1.87 \mathrm{eV})$ and $\mathrm{NO}_{2}(-1.30 \mathrm{eV})$ were strongly adsorbed on Ni-doped vacancy-defected graphene, while the $\mathrm{SO}_{2}(-0.36 \mathrm{eV})$ and $\mathrm{SO}_{3}(-0.38 \mathrm{eV})$ gases were weakly adsorbed [89]. Finally, the $\mathrm{CO}$ and $\mathrm{NO}$ adsorption on Pd-doped vacancy-defected graphene were computed using the PBE functional [60]. The computed adsorption energies of $\mathrm{CO}$ and NO molecules on Pd-doped vacancy-defected graphene were higher than on single-vacancy and pristine graphene [60].

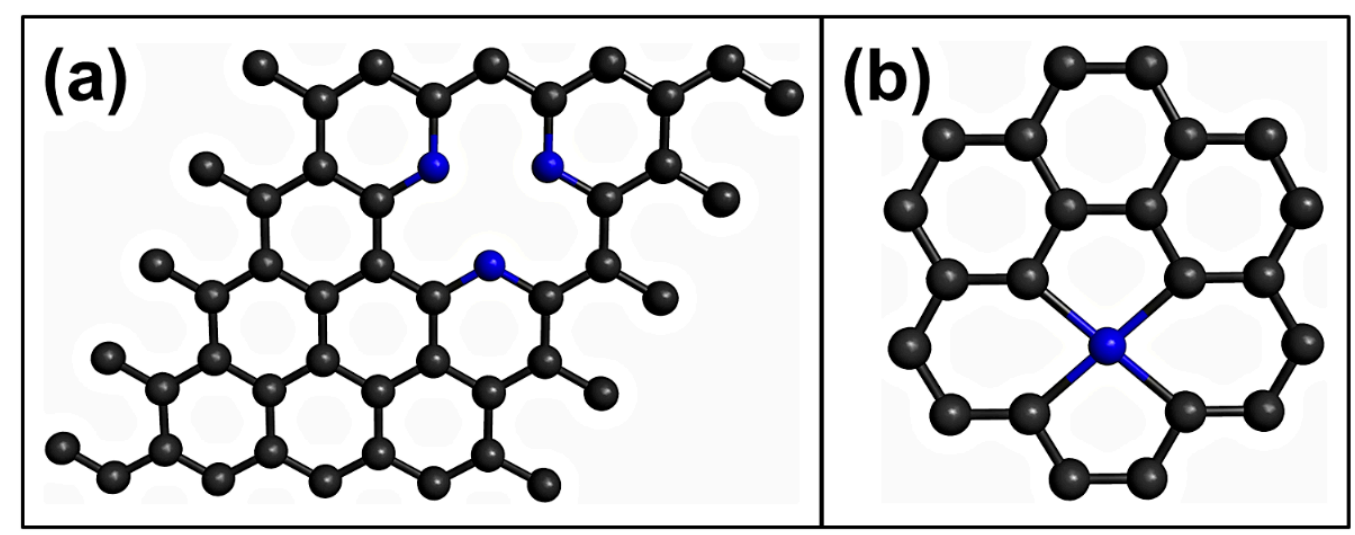

Figure 5. (a) Pyridinic-type N-doped graphene, (b) doped vacancy-defected graphene. Black and blue spheres represent $\mathrm{C}$ and $\mathrm{H}$ atoms, respectively.

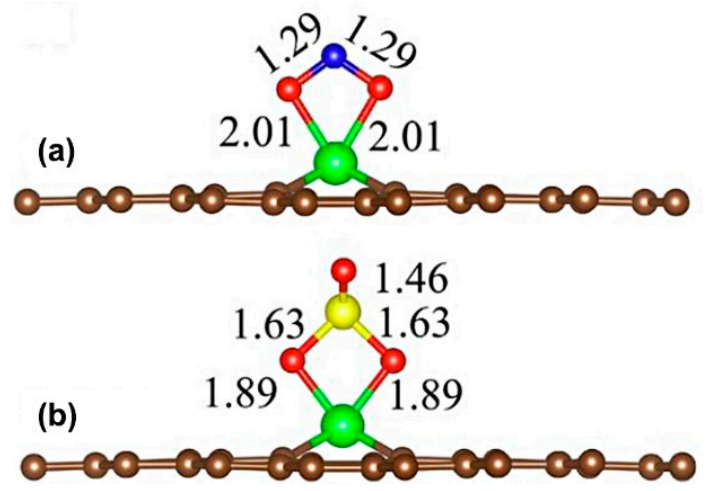

Figure 6. Most stable structures of $\mathrm{NO}_{2}\left(\right.$ a) and $\mathrm{SO}_{3}(\mathbf{b})$ adsorption on Fe-doped vacancy-defected graphene (The bond length in $\AA$ ). Brown, green, red, blue, and yellow spheres represent $\mathrm{C}, \mathrm{Fe}, \mathrm{O}, \mathrm{N}$, and $\mathrm{S}$ atoms, respectively. Figure modified from [80].

Many theoretical studies have been conducted on the use of doped graphene as toxic gas sensors. The results evidence that doped graphene sheets are good candidate materials as gas sensors. To experimentally confirm some of the above-mentioned theoretical predictions, various doped graphene materials have been synthesized and evaluated as toxic gas sensors [103-108]. Based on experimental evidence, the sensitivity and selectivity of doped graphene were higher than pristine graphene [103-107]. However, it is difficult to control the doping concentration and the number of graphene layers. Hence, future trends should be focused on the improvement of doped graphene gas sensors through novel, low-cost industrially scalable techniques that allow to control the doping concentration and type in graphene. 


\section{Conclusions and Perspectives}

This review presents a detailed and critical analysis of current progress of graphenebased toxic gas sensors using first-principle methods. Following the development of graphene as a gas sensor, it has gained considerable interest from both a theoretical and a technological viewpoint. Therefore, modifications made to graphene to improve the detection of $\mathrm{CO}, \mathrm{NO}_{\mathrm{x}}$, and $\mathrm{SO}_{\mathrm{x}}$ toxic gases were revised and analyzed in detail. Based on this review, we concluded the following:

(a) The interaction between toxic gases and pristine graphene is weak, which reduces the sensitivity and selectivity of pristine graphene toward the toxic gases.

(b) The pristine graphene decorated with transition metals is a promising material for use in a toxic gas sensor. However, up to now these types of studies are still scarce; therefore, more theoretical studies on the sensitivity and selectivity of pristine graphene decorated with transition metals toward the toxic gases should be carried out.

(c) It was observed that graphene with single-vacancy defects interacts stronger with the toxic gases compared to pristine graphene. Therefore, it is a promising material for use in toxic gas sensors. In addition to point defects, line or multivacancy defects should be investigated at the DFT level, to enrich graphene functionalities.

(d) Bilayer and multilayer graphene exhibit higher different dimensionalities than singlelayer graphene, which can increase the number of possible defect types, namely, point defects, line defects, and so on. At the theoretical level, more attention should be paid to understanding stable bilayer and multilayer graphene with randomly distributed defects.

(e) A large number of theoretical studies have addressed the use of doped graphene as a toxic gas sensor. The evidence indicates that doped-graphene sheets are good candidate materials. However, up to date, DFT studies on the selectivity of doped graphene toward the toxic gases are limited. Therefore, more theoretical studies on the selectivity of doped graphene toward the toxic gases should be carried out. In addition, feasible approaches to facilitate the desorption of toxic gas on the doped graphene surface should be investigated.

(f) The pyridinic-type $\mathrm{N}$-doped graphene and doped vacancy-defected graphene are good materials for use in toxic gases sensors. However, more DFT-based studies on pyridinic-type $\mathrm{N}$-doped graphene and doped vacancy-defected graphene as toxic gas sensors are needed.

(g) The reasons for the difference of adsorption energy obtained by using different functionals (e.g., GGA, LDA, PBE, and vdW-DF2) in the calculation methods should be compared and analyzed.

(h) This review shows the importance of theoretical studies for the design of novel and efficient toxic gas sensors. The theoretical results obtained up to now can help and motivate experimental groups to design novel and efficient graphene-based toxic gas sensors.

Author Contributions: Conceptualization, H.C.-M., H.R.-C., F.M.-A., and D.I.M.; formal analysis, H.C.-M., F.M.-A., Y.A.P.-C., and D.I.M.; investigation, H.C.-M., H.R.-C., F.M.-A. and Y.A.P.-C.; data curation, H.C.-M., H.R.-C., F.M.-A. and Y.A.P.-C.; writing-original draft preparation, H.C.-M., H.R.-C., P.T.M.-O. and D.I.M.; writing-review and editing, H.C.-M., H.R.-C., P.T.M.-O. and D.I.M.; funding acquisition, D.I.M. All authors have read and agreed to the published version of the manuscript.

Funding: The article processing charges was funded by Tecnologico de Monterrey.

Institutional Review Board Statement: Not applicable.

Informed Consent Statement: Not applicable.

Data Availability Statement: Not applicable.

Acknowledgments: The author H. Rojas-Chávez appreciates the resource provided by the "Reconocimiento a Perfil Deseable y Apoyo 2019".

Conflicts of Interest: The authors declare no conflict of interest. 


\section{References}

1. Tian, W.; Liu, X.; Yu, W. Research progress of gas sensor based on graphene and its derivatives: A review. Appl. Sci. 2018, 8, 1118. [CrossRef]

2. Mahajan, S.; Jagtap, S. Metal-oxide semiconductors for carbon monoxide (CO) gas sensing: A review. Appl. Mater. Today 2020, 18, 100483. [CrossRef]

3. Rose, J.J.; Wang, L.; Xu, Q.; McTiernan, C.F.; Shiva, S.; Tejero, J.; Gladwin, M.T. Carbon monoxide poisoning: Pathogenesis, management, and future directions of therapy. Am. J. Respir. Crit. Care Med. 2017, 195, 596-606. [CrossRef] [PubMed]

4. Hampson, N.B.; Bodwin, D. Toxic CO-ingestions in intentional carbon monoxide poisoning. J. Emerg. Med. 2013, 44, 625-630. [CrossRef] [PubMed]

5. Raub, J.A.; Mathieu-Nolf, M.; Hampson, N.B.; Thom, S.R. Carbon monoxide poisoning-a public health perspective. Toxicology 2000, 145, 1-14. [CrossRef]

6. Gholami, F.; Tomas, M.; Gholami, Z.; Vakili, M. Technologies for the nitrogen oxides reduction from flue gas: A review. Sci. Total Environ. 2020, 714, 136712. [CrossRef]

7. Zhang, D.; Liu, Z.; Li, C.; Tang, T.; Liu, X.; Han, S.; Lei, B.; Zhou, C. Detection of $\mathrm{NO}_{2}$ down to ppb levels using individual and multiple $\mathrm{In}_{2} \mathrm{O}_{3}$ nanowire devices. Nano Lett. 2004, 4, 1919-1924. [CrossRef]

8. Niu, H.; Leung, D.Y.C. A review on the removal of nitrogen oxides from polluted flow by bioreactors. Environ. Rev. 2010, 18, 175-189. [CrossRef]

9. Su, Y.; Wang, J.; Wang, B.; Yang, T.; Yang, B.; Xie, G.; Zhou, Y.; Zhang, S.; Tai, H.; Cai, Z.; et al. Alveolus-inspired active membrane sensors for self-powered wearable chemical sensing and breath analysis. ACS Nano 2020, 14, 6067-6075. [CrossRef]

10. Nascimento, A.P.; Santos, J.M.; Mill, J.G.; de Almeida Albuquerque, T.T.; Júnior, N.C.R.; Reisen, V.A.; Pagel, É.C. Association between the incidence of acute respiratory diseases in children and ambient concentrations of $\mathrm{SO}_{2}, \mathrm{PM}_{10}$ and chemical elements in fine particles. Environ. Res. 2020, 188, 109619. [CrossRef] [PubMed]

11. Yang, W.; Omaye, S.T. Air pollutants, oxidative stress and human health. Mutat. Res. Genet. Toxicol. Environ. Mutagen. 2009, 674, 45-54. [CrossRef] [PubMed]

12. Springer, K.J. Global What? Control Possibilities of $\mathrm{CO}_{2}$ and Other Greenhouse Gases. J. Eng. Gas Turbines Power 1991, 113, 440-447. [CrossRef]

13. Khan, M.; Rao, M.; Li, Q. Recent advances in electrochemical sensors for detecting toxic gases: $\mathrm{NO}_{2}, \mathrm{SO}_{2}$ and $\mathrm{H}_{2} \mathrm{~S}$. Sensors 2019, 19, 905. [CrossRef] [PubMed]

14. Zhang, D.; Wu, D.; Zong, X.; Yang, Z. Enhanced $\mathrm{SO}_{2}$ gas sensing properties of metal organic frameworks-derived titanium dioxide/reduced graphene oxide nanostructure. J. Mater. Sci. Mater. Electron. 2019, 30, 11070-11078. [CrossRef]

15. Lins, V.F.C.; Guimarães, E.M. Failure of a heat exchanger generated by an excess of $\mathrm{SO}_{2}$ and $\mathrm{H}_{2} \mathrm{~S}$ in the Sulfur Recovery Unit of a petroleum refinery. J. Loss Prev. Process. Ind. 2007, 20, 91-97. [CrossRef]

16. Najjar, Y.S.H. Gaseous Pollutants Formation and Their Harmful Effects on Health and Environment. Innov. Energy Policies 2011, 1, 1-9. [CrossRef]

17. Ma, D.; Zhang, J.; Li, X.; He, C.; Lu, Z.; Lu, Z.; Lu, Z.; Yang, Z.; Wang, Y. $\mathrm{C}_{3} \mathrm{~N}$ monolayers as promising candidates for $\mathrm{NO}_{2}$ sensors. Sens. Actuators B Chem. 2018, 266, 664-673. [CrossRef]

18. Lee, S.W.; Lee, W.; Hong, Y.; Lee, G.; Yoon, D.S. Recent advances in carbon material-based $\mathrm{NO}_{2}$ gas sensors. Sens. Actuators B Chem. 2018, 255, 1788-1804. [CrossRef]

19. Chatterjee, S.G.; Chatterjee, S.; Ray, A.K.; Chakraborty, A.K. Graphene-metal oxide nanohybrids for toxic gas sensor: A review. Sens. Actuators B Chem. 2015, 221, 1170-1181. [CrossRef]

20. Xiao, Z.; Kong, L.B.; Ruan, S.; Li, X.; Yu, S.; Li, X.; Jiang, Y.; Yao, Z.; Ye, S.; Wang, C.; et al. Recent development in nanocarbon materials for gas sensor applications. Sens. Actuators B Chem. 2018, 274, 235-267. [CrossRef]

21. Singh, V.; Joung, D.; Zhai, L.; Das, S.; Khondaker, S.I.; Seal, S. Graphene based materials: Past, present and future. Prog. Mater. Sci. 2011, 56, 1178-1271. [CrossRef]

22. Castro Neto, A.H.; Guinea, F.; Peres, N.M.R.; Novoselov, K.S.; Geim, A.K. The electronic properties of graphene. Rev. Mod. Phys. 2009, 81, 109-162. [CrossRef]

23. Choi, W.; Lahiri, I.; Seelaboyina, R.; Kang, Y.S. Synthesis of graphene and its applications: A review. Crit. Rev. Solid State Mater. Sci. 2010, 35, 52-71. [CrossRef]

24. Montejo-Alvaro, F.; Oliva, J.; Zarate, A.; Herrera-Trejo, M.; Hdz-García, H.M.; Mtz-Enriquez, A.I. Icosahedral transition metal clusters $\left(\mathrm{M}_{13}, \mathrm{M}=\mathrm{Fe}, \mathrm{Ni}\right.$, and $\left.\mathrm{Cu}\right)$ adsorbed on graphene quantum dots, a DFT study. Phys. E Low Dimens. Syst. Nanostruct. 2019, 110, 52-58. [CrossRef]

25. Milowska, K.Z.; Majewski, J.A. Graphene-based sensors: Theoretical study. J. Phys. Chem. C 2014, 118, 17395-17401. [CrossRef]

26. Imamura, G.; Minami, K.; Shiba, K.; Mistry, K.; Musselman, K.P.; Yavuz, M.; Yoshikawa, G.; Saiki, K.; Obata, S. Graphene oxide as a sensing material for gas detection based on nanomechanical sensors in the static mode. Chemosensors 2020, 8, 82. [CrossRef]

27. Varghese, S.S.; Lonkar, S.; Singh, K.K.; Swaminathan, S.; Abdala, A. Recent advances in graphene based gas sensors. Sens. Actuators B Chem. 2015, 218, 160-183. [CrossRef]

28. Yuan, W.; Shi, G. Graphene-based gas sensors. J. Mater. Chem. A 2013, 1, 10078-10091. [CrossRef]

29. Mandeep, J.; Kakkar, R. Recent Advances on Graphene-Based Gas Sensors. Russ. J. Phys. Chem. A 2020, 94, 2115-2120. [CrossRef]

30. Noei, M. DFT study on the sensitivity of open edge graphene toward $\mathrm{CO}_{2}$ gas. Vacuum 2016, 131, 194-200. [CrossRef] 
31. Varghese, S.S.; Swaminathan, S.; Singh, K.K.; Mittal, V. Ab initio study on gas sensing properties of group III (B, Al and Ga) doped graphene. Comput. Condens. Matter 2016, 9, 40-55. [CrossRef]

32. Lv, R.; Li, Q.; Botello-Méndez, A.R.; Hayashi, T.; Wang, B.; Berkdemir, A.; Hao, Q.; Elías, A.L.; Cruz-Silva, R.; Gutiérrez, H.R.; et al. Nitrogen-doped graphene: Beyond single substitution and enhanced molecular sensing. Sci. Rep. 2012, 2, 586. [CrossRef] [PubMed]

33. Kaushal, S.; Kaur, M.; Kaur, N.; Kumari, V.; Singh, P.P. Heteroatom-doped graphene as sensing materials: A mini review. RSC Adv. 2020, 10, 28608-28629. [CrossRef]

34. Duan, J.; Chen, S.; Jaroniec, M.; Qiao, S.Z. Heteroatom-doped graphene-based materials for energy-relevant electrocatalytic processes. ACS Catal. 2015, 5, 5207-5234. [CrossRef]

35. Yan, X.; Jia, Y.; Yao, X. Defects on carbons for electrocatalytic oxygen reduction. Chem. Soc. Rev. 2018, 47, 7628-7658. [CrossRef] [PubMed]

36. Dua, V.; Surwade, S.P.; Ammu, S.; Agnihotra, S.R.; Jain, S.; Roberts, K.E.; Park, S.; Ruoff, R.S.; Manohar, S.K. All-organic vapor sensor using inkjet-printed reduced graphene oxide. Angew. Chem. Int. Ed. 2010, 49, 2154-2157. [CrossRef] [PubMed]

37. Lu, G.; Park, S.; Yu, K.; Ruoff, R.S.; Ocola, L.E.; Rosenmann, D.; Chen, J. Toward practical gas sensing with highly reduced graphene oxide: A new signal processing method to circumvent run-to-run and device-to-device variations. ACS Nano 2011, 5, 1154-1164. [CrossRef] [PubMed]

38. Kohn, W.; Becke, A.D.; Parr, R.G. Density functional theory of electronic structure. J. Phys. Chem. 1996, 100, 12974-12980. [CrossRef]

39. Zeng, Y.; Lin, S.; Gu, D.; Li, X. Two-dimensional nanomaterials for gas sensing applications: The role of theoretical calculations. Nanomaterials 2018, 8, 851. [CrossRef]

40. Tang, X.; Du, A.; Kou, L. Gas sensing and capturing based on two-dimensional layered materials: Overview from theoretical perspective. Wiley Interdiscip. Rev. Comput. Mol. Sci. 2018, 8, e1361. [CrossRef]

41. Singh, E.; Meyyappan, M.; Nalwa, H.S. Flexible graphene-based wearable gas and chemical sensors. ACS Appl. Mater. Interfaces 2017, 9, 34544-34586. [CrossRef] [PubMed]

42. Yavari, F.; Koratkar, N. Graphene-based chemical sensors. J. Phys. Chem. Lett. 2012, 3, 1746-1753. [CrossRef] [PubMed]

43. Leenaerts, O.; Partoens, B.; Peeters, F.M. Adsorption of $\mathrm{H}_{2} \mathrm{O}, \mathrm{NH}_{3}, \mathrm{CO}, \mathrm{NO}_{2}$, and $\mathrm{NO}$ on graphene: A first-principles study. Phys. Rev. B 2008, 77, 125416. [CrossRef]

44. Wehling, T.O.; Novoselov, K.S.; Morozov, S.V.; Vdovin, E.E.; Katsnelson, M.I.; Geim, A.K.; Lichtenstein, A.I. Molecular doping of graphene. Nano Lett. 2008, 8, 173-177. [CrossRef] [PubMed]

45. Lin, X.; Ni, J.; Fang, C. Adsorption capacity of $\mathrm{H}_{2} \mathrm{O}, \mathrm{NH}_{3}, \mathrm{CO}$, and $\mathrm{NO}_{2}$ on the pristine graphene. J. Appl. Phys. 2013, 113, 034306. [CrossRef]

46. Silvestrelli, P.L.; Ambrosetti, A. Including screening in van der Waals corrected density functional theory calculations: The case of atoms and small molecules physisorbed on graphene. J. Chem. Phys. 2014, 140, 124107. [CrossRef] [PubMed]

47. Tang, Y.; Chen, W.; Li, C.; Pan, L.; Dai, X.; Ma, D. Adsorption behavior of Co anchored on graphene sheets toward $\mathrm{NO} \mathrm{SO}_{2}, \mathrm{NH}_{3}$, CO and HCN molecules. Appl. Surf. Sci. 2015, 342, 191-199. [CrossRef]

48. Rad, A.S.; Abedini, E. Chemisorption of NO on Pt-decorated graphene as modified nanostructure media: A first principles study. Appl. Surf. Sci. 2016, 360, 1041-1046. [CrossRef]

49. Rad, A.S.; Zareyee, D. Adsorption properties of $\mathrm{SO}_{2}$ and $\mathrm{O}_{3}$ molecules on Pt-decorated graphene: A theoretical study. Vacuum 2016, 130, 113-118. [CrossRef]

50. Song, Y.D.; Wang, L.; Wu, L.M. Theoretical study of the CO, NO, and $\mathrm{N}_{2}$ adsorptions on Li-decorated graphene and boron-doped graphene. Can. J. Chem. 2018, 96, 30-39. [CrossRef]

51. Bo, Z.; Guo, X.; Wei, X.; Yang, H.; Yan, J.; Cen, K. Density functional theory calculations of $\mathrm{NO}_{2}$ and $\mathrm{H}_{2} \mathrm{~S}$ adsorption on the group 10 transition metal (Ni, Pd and Pt) decorated graphene. Phys. E Low Dimens. Syst. Nanostruct. 2019, 109, 156-163. [CrossRef]

52. Rajasekaran, G.; Narayanan, P.; Parashar, A. Effect of point and line defects on mechanical and thermal properties of graphene: A review. Crit. Rev. Solid State Mater. Sci. 2016, 41, 47-71. [CrossRef]

53. Liu, L.; Qing, M.; Wang, Y.; Chen, S. Defects in graphene: Generation, healing, and their effects on the properties of graphene: A review. J. Mater. Sci. Technol. 2015, 31, 599-606. [CrossRef]

54. Wang, B.; Pantelides, S.T. Controllable healing of defects and nitrogen doping of graphene by CO and NO molecules. Phys. Rev. B 2011, 83, 245403. [CrossRef]

55. Hussain, T.; Panigrahi, P.; Ahuja, R. Sensing propensity of a defected graphane sheet towards $\mathrm{CO}, \mathrm{H}_{2} \mathrm{O}$ and $\mathrm{NO}_{2}$. Nanotechnology 2014, 25, 325501. [CrossRef] [PubMed]

56. Huang, B.; Li, Z.; Liu, Z.; Zhou, G.; Hao, S.; Wu, J.; Gu, B.L.; Duan, W. Adsorption of gas molecules on graphene nanoribbons and its implication for nanoscale molecule sensor. J. Phys. Chem. C 2008, 112, 13442-13446. [CrossRef]

57. Ma, C.; Shao, X.; Cao, D. Nitrogen-doped graphene as an excellent candidate for selective gas sensing. Sci. China Chem. 2014, 57, 911-917. [CrossRef]

58. Zhang, Y.H.; Chen, Y.B.; Zhou, K.G.; Liu, C.H.; Zeng, J.; Zhang, H.L.; Peng, Y. Improving gas sensing properties of graphene by introducing dopants and defects: A first-principles study. Nanotechnology 2009, 20, 185504. [CrossRef] [PubMed]

59. Tit, N.; Said, K.; Mahmoud, N.M.; Kouser, S.; Yamani, Z.H. Ab-initio investigation of adsorption of $\mathrm{CO}_{\text {and }} \mathrm{CO}_{2}$ molecules on graphene: Role of intrinsic defects on gas sensing. Appl. Surf. Sci. 2017, 394, 219-230. [CrossRef] 
60. Shukri, M.S.M.; Saimin, M.N.S.; Yaakob, M.K.; Yahya, M.Z.A.; Taib, M.F.M. Structural and electronic properties of CO and NO gas molecules on Pd-doped vacancy graphene: A first principles study. Appl. Surf. Sci. 2019, 494, 817-828. [CrossRef]

61. Yang, S.; Lei, G.; Xu, H.; Xu, B.; Li, H.; Lan, Z.; Wang, Z.; Gu, H. A DFT study of CO adsorption on the pristine, defective, In-doped and Sb-doped graphene and the effect of applied electric field. Appl. Surf. Sci. 2019, 480, 205-211. [CrossRef]

62. Jia, X.; Zhang, H.; Zhang, Z.; An, L. Effect of doping and vacancy defects on the adsorption of CO on graphene. Mater. Chem. Phys. 2020, 123114. [CrossRef]

63. Ali, M.; Tit, N. Adsorption of $\mathrm{NO}$ and $\mathrm{NO}_{2}$ molecules on defected-graphene and ozone-treated graphene: First-principles analysis. Surf. Sci. 2019, 684, 28-36. [CrossRef]

64. Zhou, Q.; Ju, W.; Su, X.; Yong, Y.; Li, X. Adsorption behavior of $\mathrm{SO}_{2}$ on vacancy-defected graphene: A DFT study. J. Phys. Chem. Solids 2017, 109, 40-45. [CrossRef]

65. Liu, X.Y.; Zhang, J.M.; Xu, K.W.; Ji, V. Improving $\mathrm{SO}_{2}$ gas sensing properties of graphene by introducing dopant and defect: A first-principles study. Appl. Surf. Sci. 2014, 313, 405-410. [CrossRef]

66. Sánchez-Rodríguez, E.P.; Vargas-Hernández, C.N.; Cruz-Martínez, H.; Medina, D.I. Stability, magnetic, energetic, and reactivity properties of icosahedral $\mathrm{M}_{\mathrm{Pd}}(\mathrm{M}=\mathrm{Fe}, \mathrm{Co}, \mathrm{Ni}$, and $\mathrm{Cu})$ core-shell nanoparticles supported on pyridinic $\mathrm{N}_{3}$-doped graphene. Solid State Sci. 2021, 112, 106483. [CrossRef]

67. Wang, X.; Sun, G.; Routh, P.; Kim, D.H.; Huang, W.; Chen, P. Heteroatom-doped graphene materials: Syntheses, properties and applications. Chem. Soc. Rev. 2014, 43, 7067-7098. [CrossRef] [PubMed]

68. Zhang, H.P.; Luo, X.G.; Lin, X.Y.; Lu, X.; Leng, Y.; Song, H.T. Density functional theory calculations on the adsorption of formaldehyde and other harmful gases on pure, Ti-doped, or N-doped graphene sheets. Appl. Surf. Sci. 2013, 283, 559-565. [CrossRef]

69. Montejo-Alvaro, F.; Oliva, J.; Herrera-Trejo, M.; Hdz-García, H.M.; Mtz-Enriquez, A.I. DFT study of small gas molecules adsorbed on undoped and N-, Si-, B-, and Al-doped graphene quantum dots. Theor. Chem. Acc. 2019, 138, 37. [CrossRef]

70. Dai, J.; Yuan, J.; Giannozzi, P. Gas adsorption on graphene doped with B, N, Al, and S: A theoretical study. Appl. Phys. Lett. 2009, 95, 232105. [CrossRef]

71. Zhang, H.P.; Luo, X.G.; Lin, X.Y.; Zhang, Y.P.; Tang, P.P.; Lu, X.; Tang, Y. Band structure of graphene modulated by Ti or N dopants and applications in gas sensoring. J. Mol. Graph. Model. 2015, 61, 224-230. [CrossRef]

72. Shao, L.; Chen, G.; Ye, H.; Wu, Y.; Qiao, Z.; Zhu, Y.; Niu, H. Sulfur dioxide adsorbed on graphene and heteroatom-doped graphene: A first-principles study. Eur. Phys. J. B 2013, 86, 54. [CrossRef]

73. Shokuhi Rad, A.; Esfahanian, M.; Maleki, S.; Gharati, G. Application of carbon nanostructures toward $\mathrm{SO}_{2}$ and $\mathrm{SO}_{3}$ adsorption: A comparison between pristine graphene and N-doped graphene by DFT calculations. J. Sulfur Chem. 2016, 37, 176-188. [CrossRef]

74. Tang, Y.; Liu, Z.; Shen, Z.; Chen, W.; Ma, D.; Dai, X. Adsorption sensitivity of metal atom decorated bilayer graphene toward toxic gas molecules (CO, NO, $\mathrm{SO}_{2}$ and $\left.\mathrm{HCN}\right)$. Sens. Actuators B Chem. 2017, 238, 182-195. [CrossRef]

75. Gao, Z.; Sun, Y.; Li, M.; Yang, W.; Ding, X. Adsorption sensitivity of Fe decorated different graphene supports toward toxic gas molecules (CO and NO). Appl. Surf. Sci. 2018, 456, 351-359. [CrossRef]

76. Wanno, B.; Tabtimsai, C. A DFT investigation of CO adsorption on VIIIB transition metal-doped graphene sheets. Superlattices Microstruct. 2014, 67, 110-117. [CrossRef]

77. Cortés-Arriagada, D.; Villegas-Escobar, N.; Ortega, D.E. Fe-doped graphene nanosheet as an adsorption platform of harmful gas molecules $\left(\mathrm{CO}, \mathrm{CO}_{2}, \mathrm{SO}_{2}\right.$ and $\left.\mathrm{H}_{2} \mathrm{~S}\right)$, and the co-adsorption in $\mathrm{O}_{2}$ environments. Appl. Surf. Sci. 2018, 427, 227-236. [CrossRef]

78. Promthong, N.; Tabtimsai, C.; Rakrai, W.; Wanno, B. Transition metal-doped graphene nanoflakes for $\mathrm{CO}_{\text {and }} \mathrm{CO}_{2}$ storage and sensing applications: A DFT study. Struct. Chem. 2020, 31, 2237-2247. [CrossRef]

79. Cortés-Arriagada, D.; Villegas-Escobar, N. A DFT analysis of the adsorption of nitrogen oxides on Fe-doped graphene, and the electric field induced desorption. Appl. Surf. Sci. 2017, 420, 446-455. [CrossRef]

80. Gao, Z.; Yang, W.; Ding, X.; Lv, G.; Yan, W. Support effects in single atom iron catalysts on adsorption characteristics of toxic gases $\left(\mathrm{NO}_{2}, \mathrm{NH}_{3}, \mathrm{SO}_{3}\right.$ and $\left.\mathrm{H}_{2} \mathrm{~S}\right)$. Appl. Surf. Sci. 2018, 436, 585-595. [CrossRef]

81. Rad, A.S.; Shabestari, S.S.; Mohseni, S.; Aghouzi, S.A. Study on the adsorption properties of $\mathrm{O}_{3}, \mathrm{SO}_{2}$, and $\mathrm{SO}_{3}$ on B-doped graphene using DFT calculations. J. Solid State Chem. 2016, 237, 204-210. [CrossRef]

82. Ao, Z.M.; Yang, J.; Li, S.; Jiang, Q. Enhancement of CO detection in Al doped graphene. Chem. Phys. Lett. 2008, 461, 276-279. [CrossRef]

83. Ao, Z.M.; Li, S.; Jiang, Q. Correlation of the applied electrical field and CO adsorption/desorption behavior on Al-doped graphene. Solid State Commun. 2010, 150, 680-683. [CrossRef]

84. Rad, A.S.; Foukolaei, V.P. Density functional study of Al-doped graphene nanostructure towards adsorption of CO, $\mathrm{CO}_{2}$ and $\mathrm{H}_{2} \mathrm{O}$. Synth. Met. 2015, 210, 171-178. [CrossRef]

85. Rad, A.S. First principles study of Al-doped graphene as nanostructure adsorbent for $\mathrm{NO}_{2}$ and $\mathrm{N}_{2} \mathrm{O}$ : DFT calculations. Appl. Surf. Sci. 2015, 357, 1217-1224. [CrossRef]

86. Ma, L.; Zhang, J.M.; Xu, K.W.; Ji, V. A first-principles study on gas sensing properties of graphene and Pd-doped graphene. Appl. Surf. Sci. 2015, 343, 121-127. [CrossRef]

87. Zhang, J.N.; Ma, L.; Zhang, M.; Zhang, J.M. Effects of gas adsorption on electronic and optical properties of palladium-doped graphene: First-principles study. Phys. E Low Dimens. Syst. Nanostruct. 2020, 118, 113879. [CrossRef] 
88. Gao, X.; Zhou, Q.; Wang, J.; Xu, L.; Zeng, W. Adsorption of $\mathrm{SO}_{2}$ molecule on Ni-doped and Pd-doped graphene based on first-principle study. Appl. Surf. Sci. 2020, 517, 146180. [CrossRef]

89. Gao, Z.; Li, L.; Huang, H.; Xu, S.; Yan, G.; Zhao, M.; Ding, Z. Adsorption characteristics of acid gases $\left(\mathrm{NO}, \mathrm{NO}_{2}, \mathrm{SO}_{2}\right.$ and $\left.\mathrm{SO}_{3}\right)$ on different single-atom nickel adsorbent: A First-Principles Study. Appl. Surf. Sci. 2020, 527, 146939. [CrossRef]

90. Ma, H.; Ma, L.; Ma, L.C. Tuning the electronic and magnetic properties of Mn-doped graphene by gas adsorption and effect of external electric field: First-principles study. Int. J. Mod. Phys. B 2019, 33, 1950166. [CrossRef]

91. Jia, X.; An, L. The adsorption of nitrogen oxides on noble metal-doped graphene: The first-principles study. Mod. Phys. Lett. B 2019, 33, 1950044. [CrossRef]

92. Lee, Y.; Lee, S.; Hwang, Y.; Chung, Y.C. Modulating magnetic characteristics of Pt embedded graphene by gas adsorption $\left(\mathrm{N}_{2}, \mathrm{O}_{2}\right.$, $\mathrm{NO}_{2}, \mathrm{SO}_{2}$ ). Appl. Surf. Sci. 2014, 289, 445-449. [CrossRef]

93. Chen, Y.; Gao, B.; Zhao, J.X.; Cai, Q.H.; Fu, H.G. Si-doped graphene: An ideal sensor for NO- or $\mathrm{NO}_{2}$-detection and metal-free catalyst for $\mathrm{N}_{2} \mathrm{O}$-reduction. J. Mol. Model. 2012, 18, 2043-2054. [CrossRef] [PubMed]

94. Dai, J.; Yuan, J. Modulating the electronic and magnetic structures of P-doped graphene by molecule doping. J. Phys. Condens. Matter 2010, 22, 225501. [CrossRef] [PubMed]

95. Liang, X.Y.; Ding, N.; Ng, S.P.; Wu, C.M.L. Adsorption of gas molecules on Ga-doped graphene and effect of applied electric field: A DFT study. Appl. Surf. Sci. 2017, 411, 11-17. [CrossRef]

96. Liang, X.; Ng, S.P.; Ding, N.; Wu, C.M.L. Thermal stability of NO on Ga-doped graphene and effect of external electric field. Comput. Mater. Sci. 2018, 151, 214-221. [CrossRef]

97. Shao, L.; Chen, G.; Ye, H.; Niu, H.; Wu, Y.; Zhu, Y.; Ding, B. Sulfur dioxide molecule sensors based on zigzag graphene nanoribbons with and without Cr dopant. Phys. Lett. A 2014, 378, 667-671. [CrossRef]

98. Kumar, J.; Nemade, H.B.; Giri, P.K. Adsorption of small molecules on niobium doped graphene: A study based on density functional theory. IEEE Electron. Device Lett. 2018, 39, 296-299. [CrossRef]

99. Wang, N.; Yang, S.; Lan, Z.; Xu, H.; Wang, Z.; Hu, Y.; Gu, H. A DFT study of the selective adsorption of $\mathrm{XO}_{2}(\mathrm{X}=\mathrm{C}, \mathrm{S}$ or $\mathrm{N})$ on Ta-doped graphene. Comput. Theor. Chem. 2020, 1190, 113003. [CrossRef]

100. Liu, X.-J.; Cao, W.-Q.; Huang, Z.-H.; Yuan, J.; Fang, X.-Y.; Cao, M.-S. Electronic structures and adsorption of Li-doped graphenes for CO. Chin. Phys. Lett. 2015, 32, 036802. [CrossRef]

101. Braubach, M.; Algoet, A.; Beaton, M.; Lauriou, S.; Héroux, M.E.; Krzyzanowski, M. Mortality associated with exposure to carbon monoxide in WHO European Member States. Indoor Air 2013, 23, 115-125. [CrossRef] [PubMed]

102. Song, Y.D.; Wang, L.; Wang, Q.T. Computational study of the $\mathrm{NO}, \mathrm{SO}_{2}$, and $\mathrm{NH}_{3}$ adsorptions on fragments of $3 \mathrm{~N}$-graphene and $\mathrm{Al} / 3 \mathrm{~N}$ graphene. J. Mol. Model. 2018, 24, 210. [CrossRef] [PubMed]

103. Guo, L.; Li, T. Sub-ppb and ultra selective nitrogen dioxide sensor based on sulfur doped graphene. Sens. Actuators B Chem. 2018, 255, 2258-2263. [CrossRef]

104. Lv, R.; Chen, G.; Li, Q.; McCreary, A.; Botello-Méndez, A.; Morozov, S.V.; Liang, L.; Declerck, X.; Perea-Lopez, N.; Cullen, D.A.; et al. Ultrasensitive gas detection of large-area boron-doped graphene. Proc. Natl. Acad. Sci. USA 2015, 112, 14527-14532. [CrossRef] [PubMed]

105. Turner, S.; Yan, W.; Long, H.; Nelson, A.J.; Baker, A.; Lee, J.R.; Carraro, C.; Worsley, M.A.; Maboudian, R.; Zettl, A. Boron doping and defect engineering of graphene aerogels for ultrasensitive $\mathrm{NO}_{2}$ detection. J. Phys. Chem. C 2018, 122, 20358-20365. [CrossRef]

106. Shaik, M.; Rao, V.K.; Gupta, M.; Murthy, K.S.R.C.; Jain, R. Chemiresistive gas sensor for the sensitive detection of nitrogen dioxide based on nitrogen doped graphene nanosheets. RSC Adv. 2016, 6, 1527-1534. [CrossRef]

107. Srivastava, S.; Kashyap, P.K.; Singh, V.; Senguttuvan, T.D.; Gupta, B.K. Nitrogen doped high quality CVD grown graphene as a fast responding $\mathrm{NO}_{2}$ gas sensor. New J. Chem. 2018, 42, 9550-9556. [CrossRef]

108. Niu, F.; Shao, Z.W.; Gao, H.; Tao, L.M.; Ding, Y. Si-doped graphene nanosheets for $\mathrm{NO}_{\mathrm{x}}$ gas sensing. Sens. Actuators B Chem. 2021, 328, 129005. [CrossRef] 